\title{
Modeling and experimental investigation of fracture behavior of hot-rolled hypereutectoid Si-Mn TRIP steel: The heat-treatment effect
}

\author{
Sasan Hasanlou ${ }^{1}$, Majid Vaseghi ${ }^{1}$, and Mahmood Sameezadeh ${ }^{1}$ \\ ${ }^{1}$ Shahid Beheshti University
}

July 27, 2020

\begin{abstract}
The aim of this study was to investigate the fracture and hardening behaviors of TRIP steel at different heat-treatments using the uniaxial tensile test and the necking correction method. The uniaxial tensile tests were performed on samples heat-treated through different procedures and strain rates in the range of $0.005-5 \mathrm{~s}-1$. It was observed that the strain rate slightly affects the formability of TRIP steel in different heat-treatment procedures. The obtained results showed that the H3 sample had the highest strain fracture. The nucleation and growth of voids, as well as the dynamic equilibrium between strain hardening and recovery, were reasons for fracture strain increment from 0.005 to $0.1 \mathrm{~s}-1$. However, fracture strain decreased at the strain rate of $0.1-5 \mathrm{~s}-1$ due to the decrease of ductility. Also, TRIP steel characterizations were used for modeling the displacement and stress of the anti-roll bar by ANSYS parametric language and Solid-Works. The displacement and stress results of TRIP steel were compared to other materials.
\end{abstract}

\section{Hosted file}

A2 hasanlo 990506-FFEMS.docx available at https://authorea.com/users/346565/articles/ 472520-modeling-and-experimental-investigation-of-fracture-behavior-of-hot-rolledhypereutectoid-si-mn-trip-steel-the-heat-treatment-effect 